\title{
a16z Brings Thought Leadership to the Valley
}

\author{
Robert Buday (Buday Thought Leadership Partners) \\ Charles Eesley (Stanford University) \\ James C Wetherbe (Texas Tech University)
}

KEYWORDS: Marketing, Venture Capital, Startups.

Back in the depths of the Great Recession, two World Wide Web pioneers set up shop on Menlo Park, Calif.'s venture capital enclave, Sand Hill Road. Marc Andreessen and Ben Horowitz of early Web browser Netscape fame had come very late to the VC party in 2009, some 50 years after the sector began gaining traction in Silicon Valley. Nonetheless they have quickly changed how notoriously thinly staffed and tight-lipped VC firms organize and market themselves to fund investors and entrepreneurs.

In doing so, Andreessen Horowitz has rocketed to the top tier of venture capital firms, in 2021 ranking $13^{\text {th }}$ globally in leading or co-leading in venture and growth-stage rounds, with $\$ 7$ billion in investments.[1]

(denied:applewebdata://597E6EFC-4607-4555-83A8-D 6E20E9AECD1\#_ftn1) It manages $\$ 28$ billion in assets across multiple funds today.[2]

(denied:applewebdata://597E6EFC-4607-4555-83A8-D 6E20E9AECD1\#_ftn2) Some of its most notable portfolio companies have been Facebook, Twitter, Airbnb, Pinterest, and Slack, which after going public or being sold are collectively worth hundreds of billions of dollars today.

The rise of "a16z" (the company's shorthand for itself, based on the 16 letters between the first and last letters of its title), holds important lessons for today's technology startups and their investors. They should consider key elements of the a16z playbook to be in their playbook too -- especially in today's world, where the commercial potential of breakthrough technologies can be hard for investors and entrepreneurs to fathom.

This article explores how a16z changed the VC industry's approach to marketing and nurturing the entrepreneurs that it funds; how other VC firms have adopted a similar path; and how other investors and startups can adopt some of a16z's most potent strategies.

In short and as we view it, a16z has raised the practice of thought leadership to a whole new level in the VC industry. By doing so, it has attracted billions of dollars of investments and top-tier entrepreneurs into its fold. It has also loaded up its portfolio firms with expertise that has helped many of them become hugely successful businesses.

\section{The Primacy of Thought Leadership}

Thought leadership marketing has been a big differentiator for $16 z$. This kind of marketing, aimed first at educating rather than selling, is different from product and brand marketing, both of which are also important.

Rather than merely point to the successful companies it funded, $a 16 z$ has been catching investor and entrepreneur attention with big ideas about how technology will change business. One of the first was about the future of the software industry, introduced to the world through a long and since often-quoted 2011 Wall Street Journal op-ed that Andreessen wrote ("Why Software is Eating the World"[3]

(denied:applewebdata://597E6EFC-4607-4555-83A8-D 6E20E9AECD1\#_tn3) ). Others have been about blockchain technology and the latest craze in the Valley, "Web3," a vision about the next big stage in the internet's commercialization.

As part of an early wave of VCs and investors who began to blog about entrepreneurship and venture capital, Andreessen (with his popular blog "pmarca") mastered this format and built a following. In 2014, seven years after the Twitter social network emerged, his audience followed him there where he pioneered the "tweetstorm," averaging five tweets an hour for six months. No way that Andreessen would let Twitter's 140-characters-per-message limit curtail his 
writings.[4]

(denied:applewebdata://597E6EFC-4607-4555-83A8-D 6E20E9AECD1\#_ftn4)

a16z has been catching investor and entrepreneur attention with big ideas about how technology will change business.

a16z has taken an innovative approach to supporting firms in its portfolio, scaling up the supply of valuable expertise in business development, finance, recruiting and marketing. As a Forbes reporter wrote three years ago, it was a Hollywood talent agency model rather than the traditional VC model.[5]

(denied:applewebdata://597E6EFC-4607-4555-83A8-D 6E20E9AECD1\#_ftn5)

To be sure, we are not saying that a16z is the only VC firm playing the thought leadership game - over the last 13 years or before then. Other VCs have made investments in thought leadership marketing. Kleiner Perkins, one of the oldest VCs in Silicon Valley, has published two best-selling books in the last four years and has had a podcast series since 2020 called "Go to Market Grit." At another oldline VC firm, Greylock Partners, investor Reid Hoffman has been the host of a highly popular podcast called "Masters of Scale." Paul Graham (Y Combinator), Fred Wilson (Union Square Ventures), and Brad Feld (Foundry Group and Mobius Venture Capital) among others have widely followed blogs that raised their profiles among entrepreneurs and investors.

However, in our view a16z has taken this to a new level in VC circles. It not only publishes its views, it also hires staff with expertise in all the complementary functions that a VC-funded firm will need. This ranges from design and user testing, to digital marketing, to arranging meetings for startups with potential large company customers, all in service of the direction that a16z sees the world moving.

To shed further light on what $\mathrm{a} 16 \mathrm{z}$ is doing, we first take a look back at the last three decades of tech-topic narrative shaping. We assert that it was a period in which venture capital and tech companies took a back seat to consultants and academics who largely shaped the narratives on the importance and future impact of emerging technologies. In the future, tech companies and VCs like a16z must do the shaping.

\section{Leaders in Tech-Related Thought Leadership in the 1990s and 2000s}

For 30 years, we have seen a pronounced cycle of thought leadership on information technology topics:

- Management consulting/tech research/university professors study how a small set of pioneer companies are using a new technology, and then ...

- Formulate best practices for all companies to capitalize on the technology, and then ...

- Disseminate those practices in journal articles, speeches, books, and other content ...

- Which accelerates the widespread adoption of the technology

The evidence is substantial. Business reengineering, the concept that one of us helped market at the consulting firm CSC Index in the early 1990s, coincided with the rapid uptake of enterprise resource management systems (especially those sold by SAP) later that decade. Reengineering guru Michael Hammer would later view SAP is an integral tool for crossfunctional business processes. Consulting firm Bain \& Co. wrote pioneering articles on customer loyalty management practices that decade (and later, the Net Promoter Score), which we believe helped greatly accelerate adoption of CRM software sold first by the likes of Siebel and later by Salesforce.com.

The consultant and academic thought leadership-fueled adoption of digital technology has continued ever since. A 2015 Harvard Business Review cover article ("How Smart, Connected Products are Transforming Companies")[6]

(denied:applewebdata://597E6EFC-4607-4555-83A8-D 6E20E9AECD1\#_tn6) by legendary Harvard Business School strategy professor Michael Porter and the CEO of a product lifecycle management software firm (James Heppelmann of PTC) coincided with an explosion in the growth of Internet of Things technologies such as digital sensors embedded in products like cars and construction equipment. PTC's revenue, which had been stuck at around $\$ 1$ billion for years, has risen $80 \%$ since their $H B R$ article was published. 


\begin{tabular}{|r|l|}
\hline \multicolumn{2}{|c|}{ THE THOUGHT LEADERSHIP/DIGITAL TECHNOLOGY } \\
HIT PARADE
\end{tabular}

But the tech thought leadership playing field has become much more crowded since the turn of the century, in part because spending on information technology has exploded. There's much more money to be grabbed by consulting firms, IT services firms, research houses, financiers, universities and others that can capture mindshare. Thought leaders on tech help buyers sort out what real from what's hype.

Thought leaders on tech help buyers sort out what real from what's hype.

That's increasingly difficult to do, given the pace with which digital technology has evolved and changed the way organizations operate. No other industry illustrates this dynamic better than the media business. Its products - newspapers, magazines, books, music, and so on - can be entirely digitized and distributed online. And they have been, to fortunes of some players and the demise of many others. Since 2005, U.S. newspaper revenue has plunged $71 \%$ as competitors for online classified ads (e.g., Craigslist), display advertising (particularly Facebook and Google) and readers have been draining money out of the sector.

In contrast, a big beneficiary of the digital revolution has been the global streaming business: Netflix and the other producers and distributors of movies and other programming. The streaming sector has grown enormously -- propelled by higher bandwidth broadband connections, viewing devices that people can take anywhere (their smartphones and tablet computers), and cloud computing data centers by the likes of Amazon Web Services and Microsoft that enable millions of people to watch digital video concurrently. Globally, revenue from subscription video on demand increased more than threefold between 2016 and 2021 to more than $\$ 55$ billion, according to PwC's Global Entertainment \& Media Outlook (https://www.pwc.com/gx/en/entertainmentmedia/outlook-2021/perspectives-2021-2025.pdf) 2021-2025.[7] (denied:applewebdata://597E6EFC-4607-4555-83A8-D 6E20E9AECD1\#_ftn7)

That kind of disruptive change is mind-numbing for the executives going through it. It's also more difficult for professors, consultants, and research firms to assess technology's consequential impacts quickly and accurately enough.

The inventors of the future are those who create the platforms to be communicators of thought leadership.

VCs like a16z apparently have decided they don't need to wait for these traditional thought leaders to sort out the "best practices." Said another way, the inventors of the future are those who create the platforms to be communicators of thought leadership. In the old VC world, there were inventors and there were great communicators. The latter included professors and consultants who studied best practices in the adoption of emerging technologies. A16z is an inventor that understands inventors - and thought leadership.

As Vijay Gurbaxani, a leading thinker on the business impact of digital technology and leader of the University of California Irvine's Center for Digital Transformation, told us: "Each new consequential technology requires fundamental changes in management practices. But 
these changes are not immediately apparent to companies that could buy the technology. Tech firms must be among the ones to articulate those changes."

Or as "Crossing the Chasm" author and legendary tech marketing strategist Geoffrey Moore so aptly put it in his endorsement of Buday's new book on thought leadership: "Thought leadership is the engine that drives the early adoption of disruptive innovation. It inspires visionary customers not only to embrace a new paradigm but to set aside budget to incorporate it into their future plans."

\section{How a16z Changed the VC Marketing Playbook}

Andreessen Horowitz realized the need to supply thought leadership externally and internally soon after it started. The two founders helped foment the Web's early transformation of business in their Netscape days of the 1990s. Andreessen, Horowitz, and most recently a16z general partner Andrew Chen (author of a new book, "The Cold Start Problem," on scaling up firms that benefit from "network effects") have been putting their broad strokes on the business/tech landscape.

In its first five years, a16z raised about $\$ 4$ billion in capital, 10 years sooner than it took another top-tier venture firm, Summit Partners, according to Peter Sims, a former Summit employee(https://thoughts.siliconguild.com/how-andree ssen-horowitz-is-disrupting-silicon-

valley-208041d6375d)

.[8]

(denied:applewebdata://597E6EFC-4607-4555-83A8-D 6E20E9AECD1\# ftn8) Since then, the firm has further climbed even further in the VC stratosphere. In 2021, it was on pace to strike four times the number of deals (221) than it made in 2017, according to CB Insights.[9]

(denied:applewebdata://597E6EFC-4607-4555-83A8-D 6E20E9AECD1\#_ftn9)

a16z took a unique strategy in using its management fees: not to pay its founders in the early years. Instead, it hired staff with skills in high demand at startups that shared its vision of "software eating the world." These valued-added services went far beyond money. They had long been provided by other VC firms (see Emily Pahnke's

article(https://eiexchange.com/content/367-Bankers-orbrokers-for-favored-firms-VCs-invest) in EIX), yet typically in a haphazard way through introductions or maybe a single recruiter on staff. Instead, a16z took this idea and ran with it, hiring dozens of experts in user experience and interface designers, digital marketing and social media, and organizing meetings with large companies that could be customers, suppliers, funders or acquirers. Andreessen Horowitz' thought leadership marketing comes into play here too, by helping attract these companies into the a16z orbit.

The firm's marketing has been termed "shaping the narrative" on the impact and future potential of digital technology. Or as Sims said, "The way Andreessen and Horowitz market their firm and themselves is by producing 'thought leadership,'” pointing to a book that Horowitz published on entrepreneurship before he and Andreessen launched the firm.

The firm's marketing has been termed "shaping the narrative" on the impact and future potential of digital technology.

Other VC firms - even some of the old guard apparently have taken notice. For example, Kleiner Perkins partner John Doerr just published a book about dealing with climate change, called "Speed \& Scale (https://speedandscale.com/), , that landed on the Wall Street Journal bestseller list at the end of 2021. (Doerr published a 2018 NY Timesbestseller called "Measure What Matters").

But a16z is the one that changed the narrative on VC marketing, according to journalists covering Silicon Valley. "If you look at the landscape of venture capital firms at the time, the list of the top 4 or 5 firms was basically etched in stone," said a16z's marketing chief, Margit Wennmachers, in a recent company podcast (https://a16z.com/2019/11/20/brand-building-a16zideas-people-marketing/) . "Guess how that list marketed itself? With the logos of the companies they had invested in. It was basically reference selling."

\section{Embracing the Spotlight}

Dealing with the press used to be something that many VC firms would avoid. "Before Andreessen Horowitz launched in the summer of 2009, most venture capital firms believed that no press was good press," wrote Jessi Hempel in a 2018 Wired magazine article 
(https://www.wired.com/story/margit-wennmachers-isandreessen-horowitzs-secret-weapon/) about Wennmachers. "They remained lean, behind-thescenes outfits and won deals because of their backroom reputations."

The narrative shaping for this audience is about how digital technology is changing the business landscape. In hiring Wennmachers, the two a16z founders wanted a communications pro who could help them, other a16z partners and the firm's portfolio companies develop such narratives. The goal, as Andreessen told the Wired (https://www.wired.com/story/margit-wennmachers-isandreessen-horowitzs-secret-weapon/) magazine reporter, was to create "the bat signal that if you're an engineer or entrepreneur trying to build something fundamentally new, we want you to come to us because we're the people who understand this stuff." [10]

(denied:applewebdata://597E6EFC-4607-4555-83A8-D 6E20E9AECD1\#_ftn10)

Often, the best way to defend oneself in the world of ideas is to shape those ideas, to author them.

As Hempel wrote at Wired about Wennmachers: "In [her] view, communications rests on a single choice: One plays offense or defense. Defense, of course, is table stakes. It must be done. But, often, the best way to defend oneself in the world of ideas is to shape those ideas, to author them. To play offense." As Wennmachers herself described it to Wired: "The best role for us to play is to explain technology, explain the future, explain how it works, explain the potential implications. We just need to double down on it." (She's also a partner at a16z, which Bloomberg Businessweek termed "an unprecedented move for the traditionally lowkey

industry.")[11]

(denied:applewebdata://597E6EFC-4607-4555-83A8-D 6E20E9AECD1\#_ftn11)

As anarticle(https://news.crunchbase.com/news/underthe-hood-a-decade-after-software-is-eating-the-worldandreessen-horowitz-has-its-best-exit-year-yet/)inJune in Crunchbase put it, "While [Andreessen Horowitz] may not be the oldest or the biggest venture firm in the
Valley, it is arguably the loudest and most influential." And as a former employee (Benedict Evans) said, "A16Z is a media company that monetizes through VC."

Hugely popular op-eds, $500+$ podcasts, and several popular business books later, a16z has been laying down the thought leadership marketing path for Silicon Valley VCs.

\section{a16z's Next Steps in Thought Leadership}

The narratives that Andreessen Horowitz have brought to market since its start have been provocative. One of its first was that "Software is eating the world." That was the title of an op-ed article they published in 2011 in the Wall Street Journal. At the time, technology stocks were getting hammered. Andreessen pointed to the all-time low price/earnings ratios for large publicly held tech firms.[12]

(denied:applewebdata://597E6EFC-4607-4555-83A8-D 6E20E9AECD1\#_ftn12)

Wrote Andreessen: "My own theory is that we are in the middle of a dramatic and broad technological and economic shift in which software companies are poised to take over large swaths of the economy." In that category of software companies he put companies whose operations to a great degree are run by software, even if they don't sell it: Amazon, Spotify, Zynga, movie maker Pixar, Google, Linkedin, Netflix and others.

a16z followed that op-ed with a steady drumbeat of narratives meant to shape investors and tech entrepreneurs' thinking, and attract both camps to the firm. So serious is a16z at shaping the tech narrative that it launched a thought leadership publication it calls "Future," one that it will create a separate media property for. The company's goal is to be "the go-to place for understanding and building the future, for anyone who is building, making, or curious about tech."[13]

(denied:applewebdata://597E6EFC-4607-4555-83A8-D 6E20E9AECD1\#_tn13) "Future" seeks the best views of visionaries inside and outside a16z. It's like Harvard Business Review for technology people, but without the traditional publishing and academic gatekeepers.

If executed well, "Future" should continue to attract investors to a16z's funds, as well as budding and established entrepreneurs into its fold. 


\section{Takeaways for Today's VCs}

We argue that, like a16z, tech entrepreneurs and their investors everywhere must shape their markets' narratives about the problems in the world they address, and why their product and service offerings are a superior solution to them. For VCs, this means not only marketing their expertise (creating demand with thought leadership) but also programmatically delivering it to their portfolio companies (creating supply). This requires providing an entire set of value-added activities to make that new narrative a reality, and bringing the right talent on to do this work.

VCs should also think about how to get involved in the type of primary research that produces the most compelling thought leadership: case study interviews with companies that have already implemented the technologies in their domain, and then sorting out what the most successful users of the technology did differently than the worst. This is the type of research that has led to some of the biggest market-shaping thought leadership ideas of the last 30 years: business reengineering (Michael Hammer and CSC Index), disruptive innovation (Clayton Christensen and Innosight), customer loyalty management (Bain \& Company), big data and analytics (Thomas $\mathrm{H}$. Davenport), and the era of smart, connected products (Michael Porter and James Heppelmann).

On this front, universities and consulting firms that already conduct case research in your domain could be good organizations to partner with (when they allow external funding of their studies). If they can shorten your time to market with big ideas, sharing intellectual credit with them might be worth it. They can also add the all-important element of external credibility.

Any VC considering a thought leadership strategy should bear in mind that taking the firm's thoughts directly to market may not be enough to build deep credibility with the audiences it wants to influence. We believe that leading academic and business publications, business and technology conferences, and other well-respected gatekeepers and influencers of opinions will continue to be vital places to present their ideas.

\section{Takeaways for Today's Entrepreneurs}

Both new and lifelong tech entrepreneurs need to seek out venture funding sources that can shape the narrative and prime the market. In today's world, tech companies and their VCs must educate customers and influencers contemplating purchasing decisions about why their technology offerings are vital. And those companies that haven't yet found customers and investors must start the ball rolling themselves.

The first thing they should do is determine whether they, in fact, need thought leadership to explain their business and its products. Those whose offerings address a complex problem of target customers with a complex solution have a thought leadership sell to make, as one of us explained in a previous EIX article (https://eiexchange.com/content/10-entrepreneurshipand-thought-leaderships-shotgun). We believe that tech entrepreneurs trying to get traction in new and still mysterious territory - for example, the metaverse, Web 3.0, quantum computing, and blockchain (not new but still hard for the layperson to comprehend) - can benefit from educating the marketplace about the business utility of these technologies. That means thought leadership. However, if you have a new cloud-based payroll service whose main benefit is much lower fees, you don't need thought leadership. Customers understand their problem (they need a payroll service), and the solution is perfectly clear (cheaper payroll processing).

If your space requires thought leadership, then you'll need to create a thought leadership strategy that includes topics you need to "own" (i.e., the core customer problems that your offering will address) for the foreseeable future; how you will develop compelling content on those problems (e.g., collecting case studies on how your customers have used your products and the benefits they've gained); and how you will take that content to market (through self-published white papers and blog posts, op-ed submissions, seminar and webinar presentations, etc.).

\section{Join the Thought Leadership Club}

No matter how strongly Andreessen Horowitz and its Sand Hill Road competitors embrace thought leadership and how effectively they execute it, this much is clear to us: Tech firms and their financiers need to be on this field. They can no longer look from the grandstands as the academics, consultants and research firms try to position themselves as the leading lights on the business implications of digital technology. 
"Making insanely great products," as Steve Jobs put it so famously 37 years ago in a magazine interview, is no longer enough for tech companies - new or old - to win. Creating a cogent narrative about the business utility of their products and why they're a superior solution to a complex problem has become just as important.

That's what Andreessen Horowitz has revealed to the tech world. If software is eating the world and (as a Fortune writer wrote this year) a16z is "eating the tech world," then perhaps it can be said that "thought leadership is eating the minds of strategic decisionmakers in our tech-driven world."

If that's the case, then whose thought leadership will achieve that lofty goal will become the next big battleground.

Robert Buday is CEO of Buday Thought Leadership Partners LLC and author of the new book, "Competing on Thought Leadership: How Great B2B Companies Turn Expertise Into Revenue" (Ideapress Publishing, 2022). Information on the book and Buday TLP can be found here(https://budaytlp.com/competing-on-thoughtleadership/) His email is bob@budaytlp.com(mailto:bob@budaytlp.com).

Charles Eesley is an associate professor at Stanford University's Department of Management Science and Engineering. At the university's Technology Ventures Program, he has been studying the role of educational, government and other institutions in spurring technology entrepreneurship. He has a PhD from the MIT Sloan School of Management, and a BS degree from Duke University.

James Wetherbe is the Richard Schulze Distinguished Professor at Texas Tech University's Rawls College of Business. Wetherbe is the founding editor of EIX. He and David Deeds (Schulze Professor of Entrepreneurship at The University of St. Thomas) launched EIX with the Schulze Family Foundation's backing in 2014. He has PhD, MBA and MIS degrees from Texas Tech University, and taught at the University of Houston, the University of Minnesota and the University of Memphis before he returned to teach at Texas Tech in 2000.
Our thanks to Jon Eckhardt, editor in chief of EIX, and a professor of entrepreneurship at the University of Wisconsin-Madison, and Mark Leiter of Leiter and Company, and formerly head of strategy at the Nielsen Company, for their input to this article.

[1]

(denied:applewebdata://597E6EFC-4607-4555-83A8-D 6E20E9AECD1\#_ftnref1) Crunchbase data. https://news.crunchbase.com/news/most-active-vcstartup-investors-tiger-global-softbank-y-combinator/

[2] (denied:applewebdata://597E6EFC-4607-4555-83A8-D 6E20E9AECD1\#_ftnref2) A16z web page, https://a16z.com/about/

[3] (denied:applewebdata://597E6EFC-4607-4555-83A8-D 6E20E9AECD1\#_ftnref3) Marc Andreessen, Wall Street Journal, Aug. 20, 2011. https://www.wsj.com/articles/S B10001424053111903480904576512250915629460

[4]

(denied:applewebdata://597E6EFC-4607-4555-83A8-D 6E20E9AECD1\#_ftnref4) Quartz, July 14, 2014. https:// qz.com/231649/marc-andreessen-first-six-months-ontwitter-were-unbelievably-epic/

[5] (denied:applewebdata://597E6EFC-4607-4555-83A8-D 6E20E9AECD1\#_ftnref5) Alex Konrad, "Andreessen Horowitz is Blowing Up the Venture Capital Model (Again)," Forbes. April, 2, 2019. https://www.forbes.com/sites/alexkonrad/2019/04/02/an dreessen-horowitz-is-blowing-up-the-venture-capitalmodel-again/?sh=33cbd7707d9f 
Dec.

9 , 2021.

[6] (denied:applewebdata://597E6EFC-4607-4555-83A8-D 6E20E9AECD1\#_ftnref6) Harvard Business Review, October 2015.

https://hbr.org/2015/10/how-smart-connected-productsare-transforming-companies

[7]

(denied:applewebdata://597E6EFC-4607-4555-83A8-D 6E20E9AECD1\#_ftnref7)

PwC.

https://www.pwc.com/gx/en/entertainment-

media/outlook-2021/perspectives-2021-2025.pdf

[8]

(denied:applewebdata://597E6EFC-4607-4555-83A8-D 6E20E9AECD1\#_ftnref8)

SiliconGuild.com.

https://thoughts.siliconguild.com/how-andreessen-

horowitz-is-disrupting-silicon-valley-208041d6375d

[9]

(denied:applewebdata://597E6EFC-4607-4555-83A8-D 6E20E9AECD1\#_ftnref9) CB Insights. https://www.cbinsights.com/reports/CB-Insights_TheFuture-According-To-Andreessen-Horowitz.pdf?

[10]

(denied:applewebdata://597E6EFC-4607-4555-83A8-D 6E20E9AECD1\#_ftnref10) Wired magazine. https://www.wired.com/story/margit-wennmachers-isandreessen-horowitzs-secret-weapon/

[11] (denied:applewebdata://597E6EFC-4607-4555-83A8-D 6E20E9AECD1\#_ftnref11) Bloomberg Businessweek, https://www.bloomberg.com/news/articles/2021-12-09/a 16z-founders-ben-horowitz-marc-andreessen-start-to-st ep-back-from-vc-firm\#: :text=Their\%20individual\%20re al\%20estate\%20decisions,co\%2Dfounded\%20for\%20 $\% 241.6 \% 20$ billion.

[12]

(denied:applewebdata://597E6EFC-4607-4555-83A8-D 6E20E9AECD1\#_ftnref12) Wall Street Journal, https://www.wsj.com/articles/SB100014240531119034 80904576512250915629460

[13]

(denied:applewebdata://597E6EFC-4607-4555-83A8-D 6E20E9AECD1\#_ttnref13) A16z web page, Jan. 25, 2021.

https://a16z.com/2021/01/25/doubling-down-marketingupdate-new-media/ 